https://doi.org/10.30910/turkjans.633548

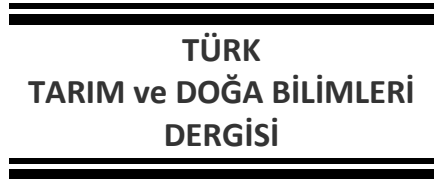

\section{Araştırma Makalesi \\ Sarı Pas (Puccinia striiformis f. sp. tritici) Hastalığına Dayanıklı Makarnalık Buğday Hatlarının Geliştirilmesi}

TURKISH

JOURNAL Of AGRICULTURAL

and NATURAL SCIENCES

www.dergipark.gov.tr/turkjans

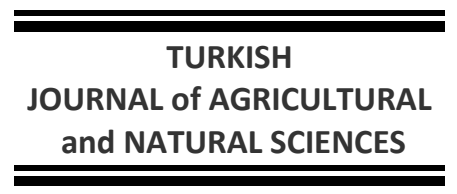
\title{
(1)
}

\author{
Kadir AKAN*

\begin{abstract}
Kırşehir Ahi Evran Üniversitesi, Ziraat Fakültesi, Bitki Koruma Bölümü Kırşehir
\end{abstract} \\ *Sorumlu yazar e-posta: kadir.akan@ahievran.edu.tr
}

\begin{abstract}
Geliş Tarihi: 06.12.2018
Düzeltme Geliş Tarihi: 13.05.2019

Kabul Tarihi: 31.07.2019

Özet

Sarı pas (Puccinia striiformis f. sp. tritici), salgını (epidemisi) oluştuğu yıllarda hastalığın şiddetine de bağlı olarak makarnalık buğday (Triticum durum)'da özellikle hassas çeşitlerin verim ve kalitesini olumsuz yönde etkilemektedir. Bu çalışmaya 2006 yılında Tarla Bitkileri Merkez Araştırma Enstitüsünde farklı ıslah programlarınca geliştirilmiş 61 makarnalık buğday hattının ön seçimi (seleksiyon) ile başlanmıştır. Bu materyal, sarı pas hastalığının 3 baskın (dominant) popülasyonlarına karşı 2006-2016 yılları arasında sera ve tarla koşullarında yapay ve doğal salgın (epidemi) şartlarında test edilmiştir. Hastalık değerlendirmeleri Modifiye Cobb skalasına göre yapılmış olup enfeksiyon katsayısı $\leq 20$ olan materyaller dayanıklı olarak değerlendirilmiştir. Araştırma materyalinin yetiştirme sezonlarına ve sarı pas hastalığı populasyonlarına göre hastalık reaksiyonlarının değişimlerini görsel olarak değerlendirmek amacıyla GGE-biplot analizi yapılmıştır. Çalışma sonucu hazırlanan GGE-biplot grafiğiyle görsel olarak dayanıklı genotipler etkin bir şekilde belirlenmiş olup yıllar üzerinden oluşturulan GGE-biplot grafiğinin PC1 ve PC2 eksenleri toplam varyasyonun \%57,67'sini açıklamıştır. Grafikte en düşük PC1 değerleri ile 0’a yakın PC2 değerleri seçilen materyallerin sarı pas hastalığına dayanıklılığını en iyi şekilde açıklamıştır. Tüm çalışma materyali, her yıl hastalığın dominant popülasyonlarına karşı dayanıklı olarak belirlenmiştir. Bu hatlar, sarı pas hastalığı dayanıklılık ıslahı çalışmalarında dayanıklılık kaynağı olarak kullanılabilir.
\end{abstract}

Anahtar kelimeler: Makarnalık buğday (Triticum durum L.), sarı pas (Puccinia striiformis), reaksiyon testi, GGEbiplot analizi, dayanıklılık kaynağı.

\section{Improvement of Durum Wheat Lines Resistant to Yellow Rust (Puccinia striiformis f. sp. tritici)}

\begin{abstract}
Yellow rust (Puccinia striiformis f. sp. tritici) has a negative effect on the yield and quality of particularly susceptible cultivars in durum wheat (Triticum durum) due to the severity of the disease during the epidemic. This study was started in 2006 at the Central Research Institute of Field Crops with the selection of 61 durum wheat lines developed by different breeding programs. This material has been tested under the conditions of artificial and natural epidemic in greenhouse and field conditions between 2006 to 2016 against 3 dominant populations of yellow rust. Disease evaluations were made according to the Modified Cobb scale and the materials with a coefficient infection of $\leq 20$ were evaluated as resistant. GGE-biplot analysis was performed to evaluate the change of disease reactions according to the growing season of the study material and the populations of yellow rust. The GGE-biplot graph, which was prepared as a result of the study, visually resistant genotypes were determined efficiently and the PC1 and PC2 axes of the GGE-biplot graph, which were formed over the years, explained $57.67 \%$ of the total variation. With the lowest PC1 values in the graph, the PC2 values close to 0 best explained the resistance of the selected materials to yellow rust. The study materials were determined to be resistant to the dominant populations of the disease every year. These lines can be used as a source of endurance in yellow rust resistance breeding studies.
\end{abstract}


Key words: Durum wheat (Triticum durum L.), yellow rust (Puccinia striiformis f. sp. tritici), reaction test, GGEbiplot analysis, resistance germplasm.

\section{Giriş}

Insan beslenmesinde ekmek ve makarna önemli yer tutmaktadır. 2017 yılı üretim sezonunda dünya da yaklaşık olarak 754 milyon ton buğday üretimi yapılmış olup üretilen bu miktarın yaklaşık 40.2 milyon tonunu makarnalık buğday oluşturmaktadır (Anonim, 2018a). Türkiye' de ki buğday ekim alanları tüm dünya buğday ekim alanlarının yaklaşık \%3.5'ini oluşturmakta olup, dünya buğday üretiminin yaklaşık $\% 3$ kadarı da ülkemizde yapılmaktadır. Dünya çapında en büyük makarnalık buğday üreticisi ülkeler sırasıyla Kanada, Italya ve Türkiye'dir (Anonim, 2018a). Türkiye de 2017 yılı üretim sezonunda 76.6 milyon dekar alanda ekmeklik buğday, 12.3 milyon dekar alanda ise makarnalık buğday üretimi yapılmıştır (Anonim 2018b). Bu ekiliş sonucu 21.5 milyon ton ekmeklik buğday ve 3.9 milyon ton makarnalık buğday üretilmiştir. Ortalama ekmeklik buğday verimi 280 $\mathrm{kg} / \mathrm{da}$, makarnalık buğday verimi ise $315 \mathrm{~kg} / \mathrm{da}$ olarak gerçekleşmiştir (Anonim 2018b). Makarnalık buğday ekiliş ve üretimin de i̇ç Anadolu ve Güneydoğu Anadolu bölgeleri dikkat çekicidir. Makarnalık buğdaydan, Avrupa ve Kuzey Amerika'da yer alan ülkelerde yaygın ürün olarak öncelikle makarna, Türkiye, Ortadoğu ve Kuzey Afrika da yer alan ülkelerde makarna üretiminin yanı sıra bulgur, kuskus, erişte ve farklı beklentileri karşılayabilen ekmek üretimi için hammadde olarak kullanıldığı bilinmektedir (Pehlivan ve Ünver İkincikarakaya, 2017).

Makarnalık buğday üretim alanlarında, önemli biyotik fungal etmenlerden biri olan pas (Puccinia spp.) hastalıkları oluşturduğu enfeksiyonlar sonucu değişen düzeylerde verim ve kalite kayıpları oluşturabilmektedir. Pas hastalıklarının gelişmesinde ve değişen düzeylerde hastalık oluşturmasında iklim faktörü kritik olup hastalığın ortaya çıkması ve zararın büyüklüğünün hastalık popülasyonun virulens desenine ve konukçu genotipine de bağlı olduğu bilinmektedir. Buğdayda pas hastalığına sebep olan önemli fungal etmenlerden birisi de sarı pas (Puccinia striiformis $\mathrm{f}$. sp. tritici) hastalığıdır. Hastalık serin ve nemli koşullarda daha etkili olabilmektedir.

$\mathrm{Bu}$ iklim şartlarının görüldüğü Anadolu yaylasının (platosunun) buğday üretimi yapılan Orta ve Batı kesimlerinin sarı pas hastalığı gelişimi için daha uygun olduğu söylenebilir. Diğer taraftan epidemi şartlarının oluştuğu farklı yıllarda birçok buğday üretim alanında hastalığın varlığı bilinmektedir (Düşünceli ve ark., 1996).

Türkiye'de sarı pas hastalığı ile ilgili ilk kaydın
M. Rasim tarafından 1886 yılında tutulduğu bildirilmiştir (Özgen ve Kınacı 1985). İren (1964) 1936-1963 yılları arasında hastalığın görüldüğü yıllarda çoğunlukla Orta ve Batı Anadolu'da ortaya çıktığı 1936, 1940, 1950 ve 1963 yıllarında hastalığın tüm ülkede etkili olduğunu bildirmiştir. Benzer şekilde Braun ve Saari (1992) 1975, 1976, 1977, 1984 ve 1991 yıllarında hastalık epidemilerinin lokal veya bölgesel düzeyde kaldığını bildirmişlerdir. 1995 yılında Çukurova bölgesinin buğday yetiştirilen alanlarında başlayan önemli bir epidemi Güneydoğu Anadolu bölgesinde de görülmüştür. Orta Anadolu Bölgesi önemli buğday yetiştiricilik alanlarında 1996 ve 1997 yıllarında geniş alanlarda sarı pas hastalığı belirlenmiş olup hastalık şiddetinin düşük düzeyde olduğu bildirilmiştir. Aynı çalışmanın devamında 1998 yılında ise incelenen üretim alanlarının \%98'inde hastalık enfeksiyonun görüldüğü özellikle Gerek-79 çeşidinin ekiliş alanlarında yüksek düzeyde epidemi oluştuğu bildirilmiştir (Düşünceli ve ark., 2000). 2009 yılında Orta Anadolu üretim alanın da Gerek 79 çeşidinde ve 2010 yılında ülkemizin güneyinde bulunan ülkelerde belirlenen yeni bir patotip veya popülasyon nedeniyle Orta Anadolu ve Güneydoğu Anadolu Bölgesinde etkili olan sarı pas hastalığı epidemisi nedeniyle önemli ürün kayıpları yaşanmıştır (Mert, 2010). 2014 ve 2015 yıllarında Trakya bölgesi üretim alanlarında farklı çeşitler üzerinde yeni bir patotip veya popülasyon varlığı nedeniyle bu bölgede etkili olan hastalık epidemisi yaşanmıştır (Anonim, 2016). İren (1964), tarafından 1963 yılında Orta ve Doğu Anadolu bölgelerinde \%35'e ulaşan ürün kayıplarının yaşandığı, Dutlu (1980) tarafından ise, 1969-1980 yılları arasında \%20-80 düzeyinde değişen oranlarda ürün kayıplarının yaşandığını rapor edilmiştir. Hastalık nedeniyle olabilecek ürün kayıplarının \%10-75 olabileceği bildirilmiştir (Aktaş, 2001). Braun ve Saari (1992) ise hastalık nedeniyle Gerek-79 çeşidinde \%13.5 ürün kaybının oluştuğu, uygun iklim şartlarında ürün kaybının \%26.5'dan daha yüksek olabileceğini bildirmişlerdir. Çukurova yetiştiricilik alanlarında 1995 yılında gözlenen epidemi nedeniyle önemli kayıpların yaşandığı, özellikle Seri 82 çeşidinin yetiştirildiği alanlarda zararın \%16,8'den başlayarak \%56,2'e kadar ulaştığı, ortalama kayıpların \%39.6 olduğu bildirilmiştir. Oluşan zarar sadece ürün verimiyle sınırlı olmayıp önemli kalite kayıplarının da yaşandığı bilinmektedir (Mamluk ve ark., 1997). 2010 yılında yaşanan sarı pas hastalığı epidemisi nedeniyle Güneydoğu Anadolu Bölgesinde 1.000.000 ton ürün kaybının olduğu tahmin 
edilmektedir (Anonim, 2018c).

Hastalığın kontrolünde genetik dayanıklılığın kullanımı, diğer savaşım yöntemleriyle karşılaştırıldığında üretici için uygulaması çok pratik ve kolay olan, insan ve çevre sağlığını en üst düzeyde koruyan savaşım metodu olarak öne çıkmakta olup "sürdürülebilir gıda güvenliğinin teminatı" ifadesini fazlasıyla hak etmektedir. Sarı pas hastalığının ortaya çıkışı ile yaşanabilecek ekonomik zararın büyüklüğü iklim koşullarına, popülasyonun virulens desenine ve konukçu genotipine bağlı olarak değişebilmektedir. Bununla birlikte genetik dayanıklıı̆̆ın kullanıımasının önündeki en büyük engellerden birisi de hastalığın doğal yapısında yer alan "virulens değişimleri" olarak kabul edilmektedir.

Kabul edilebilir düzeyde dayanıklı olarak belirlenen genotipler, virulens değişimi sonucu bu özelliklerini kaybedebilmekte ve sarı pas hastalığına karşı hassas reaksiyon gösterebilmektedirler. Bu nedenle sarı pas hastalığının ırk/ırklarının belirlenmesi ile varyasyonun ve virulensliğin anlaşılması, dayanıklılık genlerinin etkinliğinin sürekli olarak takip edilmesi hastalık yönetimi konuları için önemli olup, bir genotipin fazla sayı da patotip'e/ırk'a karşı dayanıklı olması istenmektedir.

GGE-biplot analiz yöntemi, birleşik bir analiz yöntemi olup, G (Genotip) ve GE (Genotip x Çevre interaksiyon) etkisini, iki temel değerlendirme faktörünü aynı görsel grafik üzerinde bir araya getirerek, ilgili konu üzerinde araştırma yapan araştırıcılarına, çalışmaları sonucu elde ettikleri verileri görsel çıktıyla çift yönlü değerlendirme imkanı sağlar ve bu şekilde yapılan değerlendirme GGE-biplot analizi olarak tanımlanmaktadır. Test materyalinin farklı çevrelerde bulunan aynı hastalığın farklı popülasyonlarında veya üretim sezonlarında aynı konuda yürütülen araştırmalarda elde edilen verilerin GGE-biplot analiz yöntemi kullanarak değerlendirilmesi sonucu, incelenen farklı özelliklerin birlikte görsel olarak değerlendirilmesine olanak sağladığı ve amaca yönelik materyal seleksiyonunda başarıyı olumlu yönde etkilediği için bitki ıslahı için yenilikçi bir uygulama olarak kabul edilebilir (Yau 1995, Yan ve ark. 2007)

Araştırmanın amacı; sürdürülebilir hastalığa dayanıklılık kaynaklarının geliştirilebilmesi için ayırıcı set kullanılarak patojenin virulenslik düzeyinin izlenmesi ve daha önce hastalıklara dayanıklı olarak belirlenen genotiplerin yeni belirlenen sarı pas hastalığının patotip/ırkına karşı doğal epidemi ve yapay epidemi şartlarında reaksiyonlarının belirlenmesidir. Çalışmayla, kışlık dilim yetiştiricilik şartlarına uygun ve sarı pas hastalığına kabul edilebilir düzeyde dayanıklı makarnalık buğday hatlarının geliştirilmesi amaçlanmıştır.

\section{Materyal ve Yöntem}

Çalışma materyali, Tarla Bitkileri Merkez Araştırma Enstitüsü (TARM), Hastalık ve Zararlılara Dayanıklılık Birimi tarafından geleneksel ıslah metotlarıyla geliştirilmiş ulusal ve uluslararası yürütülen ıslah programları materyali içinden 20012006 üretim sezonları arasında sarı pas hastalığına dayanıklı olarak belirlenmiş hatların içinden seçilmiştir. Hatların seçiminde "sarı pas hastalığına kabul edilebilir düzeyde dayanıkı" olması tek kriter olarak belirlenmiştir (Anonim, 2016). Seçilen materyal en az F7 kademesinde olmakla birlikte, tüm materyalin değişik kademelerde olması nedeniyle özellikle genotip safiyetinden emin olmak ve homozigotluk oranının arttırılması için tüm materyalde tek başak seçimi yapılmış ve bu tek başaklardan tekrar üretilmiş olup çeşit safiyetinin en üst seviyede olması sağlanmıştır. Çalışma materyalini oluşturan 61 genotip, 2006-2016 üretim sezonları süresince sarı pas hastalığının baskın popülasyonlarına (ırk/ırklarına) karşı sera ve tarla şartlarında tepkileri (reaksiyonları) belirlenmiştir. Bu materyale ek olarak sürdürülebilir dayanıklılık ıslah programları için çalışmalarının yürütüldüğü tüm sezonlar boyunca hastalık popülasyonun izlenmesi ve virulenslik düzeyinin değerlendirilmesi için sarı pas hastalığı ırk ayırıcı seti de çalışmada yer almıştır. Çalışmada Europe/Australasia olarak bilinen ırk ayırıcı set kullanılmış olup, genotip isimleri ve içerdiği dayanıklılık genleri Çizelge 1'de verilmiştir.

Çalışmanın fide evresi çalışmaları, Tarla Bitkileri Merkez Araştırma Enstitüsü Ankara Yenimahalle lokasyonun'da bulunan sera şartlarında yürütülmüştür. Test materyali olan 61 genotip ve ırk ayırıc sette bulunan genotipler, içinde torf bulunan $7 \times 7 \times 9 \mathrm{~cm}$. ölçülerindeki plastik materyal içerisine ekilmiştir. İki tekerrürlü olarak yürütülen çalışmalarda her bir saksıda 4 farklı genotip bulunmaktadır. Her bir genotipden $6 \pm 2$ tohum olacak şekilde ekilmiş ve tüm çalışma materyali $18 \pm 4^{\circ} \mathrm{C}^{\prime}$ de sera koşullarında yetiştirilmiştir. Materyal, ikinci yaprağın çıkmaya ( $Z$ 11-12) (Zadoks ve ark., 1974) başladığı dönem de bir önceki sezon üretim alanlarından toplanmış ve çoğaltılmış izolatlarla bulaştırılmıştır (inokule edilmiş). İnokulasyon uygulamalarında her zaman taze ürediniosporlar kullanılmıştır. Her bir sezon toplanarak üretilen izolatlar için test materyali ve ırk ayırıcı set taze ürediniosporlar 00 numara kapsüller içerisine konularak üzerine uçucu mineral yağ (Soltrol $170^{\circ}$ ) eklenmiş ve hazırlanan spor süspansiyonu materyale inokule edilmiştir. İnokulasyon sonrasında materyal, $9 \pm 1^{\circ} \mathrm{C}$ sıcaklık ve $\% 95 \pm 5$ nispi nem içeren ortamda 24 saat süreyle tutulmuştur. Süre sonunda test materyali bu bölümden alınarak yetiştirildikleri ortam olan 
$18 \pm 4^{\circ} \mathrm{C}^{\prime}$ de sera koşullarında yetiştirilmeye devam edilmiş olup, araştırma sonuna kadar materyal gerektikçe sulanmıştır. Hastalık reaksiyon değerlendirmeleri 16-18 gün sonra en az 2 defa, gerek görülen hallerde 3. kez yapılmıştır. Enfeksiyon tiplerini esas alan 0-9 skalası (McNeal ve ark., 1971) kullanılarak dayanıklı ve hassas genotipler tespit edilmiştir. Bu skalaya göre 0-6 skala değeri ile değerlendirilen materyal dayanıklı, 7-9 skala değeri ile değerlendirilen materyal ise hassas olarak gruplandırımıştır. Gruplandırma yapılırken, değerlendirmelerdeki en yüksek değer alınmıştır. Değerlendirmeye başlama aşamasında test materyali ve ırk ayırıc setle birlikte ekilen hassas kontrol genotipleri olan Little Club ve Morocco genotipleri 8-9 skalası değeri ile değerlendirilmiştir. Hassas kontrol genotipleri üzerinde yapılan bu değerlendirme sonucunda "reaksiyon testlerinin sonuçlarının güvenilir" olduğu yorumu yapılmış ve tüm materyal değerlendirilmiştir.

Çizelge 1. Kullanılan sarı pas hastalığı ırk ayırıcı setinde yer alan genotipler ve içerdikleri dayanıklılık genleri

\begin{tabular}{|c|c|c|c|c|c|c|c|c|}
\hline S.N. & $\begin{array}{l}\text { Genotipin } \\
\text { ismi }\end{array}$ & $\begin{array}{c}\text { İçerdiği } \\
\text { dayanıklılık } \\
\text { geni }\end{array}$ & S.N. & $\begin{array}{l}\text { Genotipin } \\
\text { ismi }\end{array}$ & $\begin{array}{c}\text { İçerdiği } \\
\text { dayanıklılık } \\
\text { geni }\end{array}$ & S.N. & $\begin{array}{l}\text { Genotipin } \\
\text { ismi }\end{array}$ & $\begin{array}{c}\text { İçerdiği } \\
\text { dayanıklılık } \\
\text { geni }\end{array}$ \\
\hline & \multicolumn{2}{|c|}{ Uluslararası set } & \multicolumn{3}{|c|}{ Avrupa seti } & & \multicolumn{2}{|c|}{ Ek genotipler } \\
\hline 1 & Chinese 166 & $Y r 1$ & 10 & Hybrid 46 & Yr4+ & 18 & Sonalika & Yr2, YrA \\
\hline 2 & Lee & Yr7 & 11 & Reichersberg42 & Yr7+ & 19 & Anza & YrA, Yr18 \\
\hline 3 & $\begin{array}{l}\text { Heines } \\
\text { Kolben }\end{array}$ & $Y r 6, Y r 2$ & 12 & Heines Peko & Yr6, Yr2+ & 20 & $\begin{array}{l}\text { Fed. } \\
\text { 4/Kavkaz }\end{array}$ & Yr9 \\
\hline 4 & Vilmorin & Yr3V & 13 & Nord Deprez & $\operatorname{Yr} 3 N$ & & Gereck 79 & --- \\
\hline 5 & Moro & Yr10 & 14 & Compare & $\begin{array}{l}\text { Yr8, } \\
\text { YrAPR }\end{array}$ & & Cham 1 & --- \\
\hline 6 & $\begin{array}{l}\text { Strubes } \\
\text { Dickopf }\end{array}$ & YrSD & 15 & Carstens V & $\mathrm{YrCV}$ & & & \\
\hline 7 & $\begin{array}{l}\text { Suwon92 } \times \\
\text { Omar }\end{array}$ & YrSU & 16 & Spaldings prolific & $\operatorname{YrSP}$ & & & \\
\hline 8 & Clement & Yr9, Yr2+ & 17 & Heines VII & Yr2+ & & & \\
\hline 9 & $\begin{array}{l}\text { Triticum } \\
\text { spelta }\end{array}$ & $\operatorname{Yr} 5$ & & & & & & \\
\hline
\end{tabular}

Çalışmanın tarla evresi çalışmaları, Tarla Bitkileri Merkez Araştırma Enstitüsü Ankara İkizce lokasyonunda bulunan tarlalarında yürütülmüştür.

Altmış bir genotip ve ırk ayırıcı sette yer alan genotipler, $30-35 \mathrm{~cm}$ sıra arası olan 0.5 metrelik sıralara 2 tekerrürlü olarak genellikle 10-20 Ekim tarihleri arasında elle ekilmiştir. Hassas kontrol ve inokulum kaynağı olan Little Club genotipi her 10 genotipten sonra bir sıra olacak şekilde ekilmiştir. Ayrıca denemenin çevresine mibzerle Litte Club, Morocco, Seri-82 ve Gün 91 hassas kontrol ve yayıcı genotipleri olarak ekilmiştir. Araştırmanın yapay epidemi koşullarında yürütülen kısmında bir önceki üretim sezonunda toplanarak farklı tekniklerle depolanmış ve sera şartlarında taze olarak üretilmiş etmenin ürediniosporları, inokulasyon için uygun olan zamanlarda en az 3 defa olacak şekilde uçucu madeni yağ (Soltrol $170^{\circ}$ ), su+Tween 20 ve talk pudrasına eklenerek, tercihen yağış sonrası akşam saatlerinde inokule edilmiştir. Bununla birlikte $2009-2010$ ve 20142015 üretim sezonunda kısmi olarak doğal epidemi şartlarında hastalık gelişmiş olup değerlendirmelerde bu durum da göz önüne alınmıştır. Hastalık gelişimini teşvik etmek amacıyla, tüm materyal sisleme ve/veya salma sulamayla sulanmıştır. Reaksiyon değerlendirmeleri Modifiye Cobb skalası (Peterson ve ark., 1948) ve reaksiyon tipi birlikte kullanılarak belirlenmiştir. Hassas kontrol genotiplerinde hastalık reaksiyon değerlendirmelerine $80 \mathrm{~S}$ düzeyine ulaştığında değerlendirmeye başlanılmıştır. Tüm çalışma yıllarında en az 2 defa değerlendirme yapılmış olup gerektiği durumlarda 3. kez değerlendirme yapılmıştır.

Tüm çalışma yıllarında değerlendirme sonrasında Enfeksiyon Katsayısı (EK) hesaplanmıştır. Tüm test yıllarında genellikle ikinci değerlendirme de kontrol genotiplerin olan Litte Club, Morocco, Seri-82 ve Gün 91 genotiplerin de hastalık reaksiyon $100 S$ olarak değerlendirilmiştir. Hassas kontrol genotipleri üzerinde yapılan bu değerlendirme sonucunda "reaksiyon testlerinin sonuçlarının güvenilir" olduğu yorumu yapılmış ve tüm materyal değerlendirilmiştir. Enfeksiyon katsayısı hesaplamalarında tekerrürlerdeki en yüksek skorlar dikkate alınmıştır. Araştırma materyalinin reaksiyonları, EK'sına göre gruplandırmıştır. Bu gruplandırmaya göre; $E K=0$; Immun, $E K \leq 0,1-5$; Dayanıklı, EK $\leq$ 5.1-20; Orta Dayanıklı, EK $\leq$ 20.1-40; Orta Hassas, EK $\leq$ 40.1-100; Hassas olarak belirlenmiştir. Genel değerlendirme de $E K=0-20$; Dayanıklı, EK $\leq$ 20.1-100 hassas olarak belirlenmiştir (Akan ve ark., 2016). 
Sarı pas hastalığının dominant ırk/ırklarına karşı dayanıklılığın hangi gen/genlerle kontrol edildiği sarı pas hastalığı ayırıcı seti kullanılarak belirlenmiştir. Sarı pas hastalığı ayırıcı setinin gerek fide evresi gerekse ergin bitki evresi testlerinde; ekimi, yetiştirilmesi, inokulasyonu ve değerlendirmesi test materyali ile aynı şekilde yapılmıştır.

Kabul edilebilir düzeyde dayanıklı olarak seçilen materyallerin sarı pas hastalığına reaksiyonları görsel olarak değerlendirmek ve öncelikle yerel hedefler sonrasında ülkesel/bölgesel hedeflere bağlı kalınarak hastalığa dayanıklı genetik hatlar oluşturulması amacıyla GGE-biplot (G:Genotip, + GE:Genotip-Çevre ilişkisi) grafiği tekniği kullanılarak genotip odaklı GGE- biplot grafiği (Şekil 1) oluşturulmuş (Yan ve Falk, 2002; Yan, 2014).

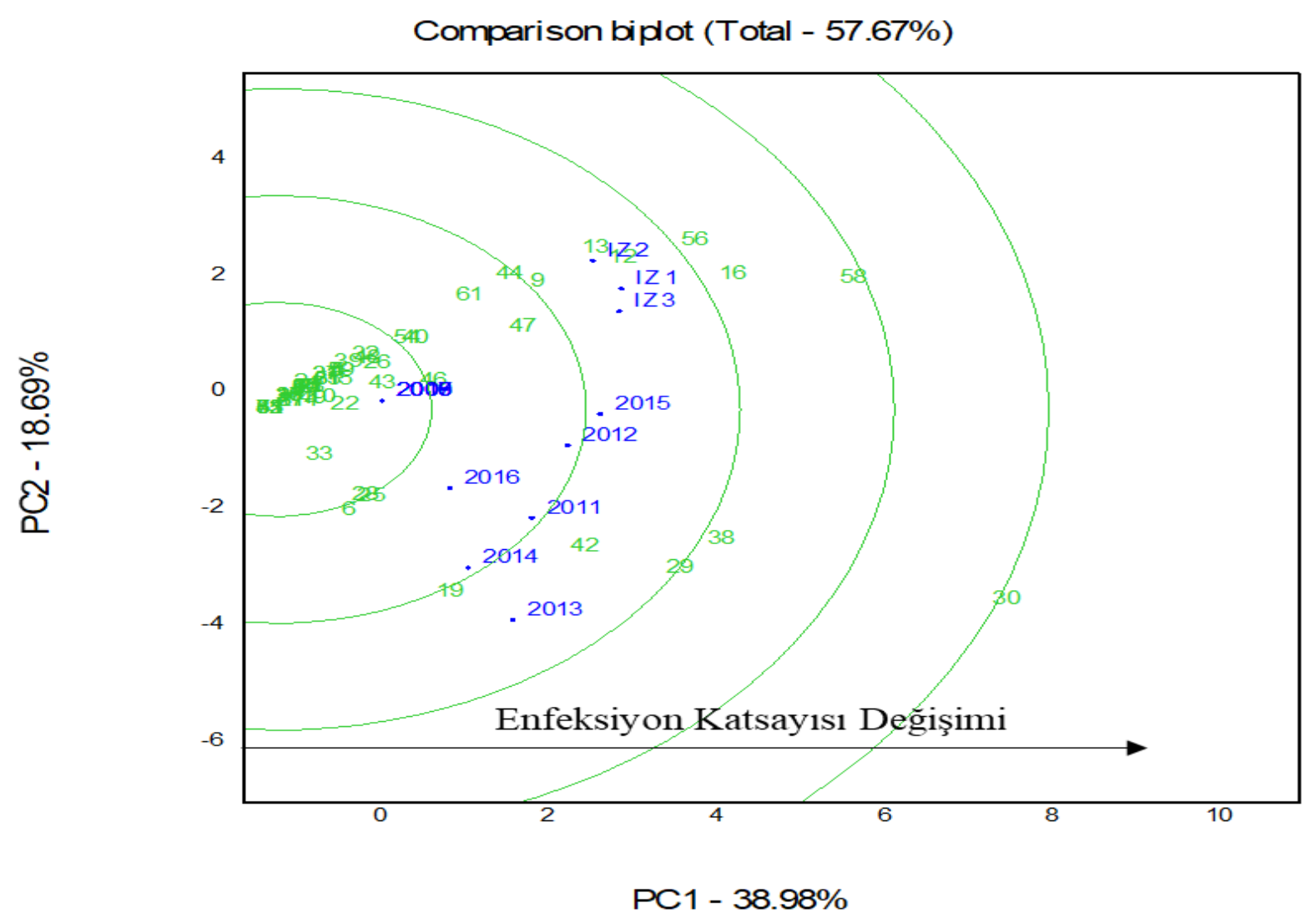

Şekil 1. Araştırma yılları üzerinden genotiplerin enfeksiyon katsayısı değişimi değerlerine göre oluşturulan GGEbiplot grafiği.

\section{Bulgular ve Tartışma}

Çalışma materyalini oluşturan 61 genotip ve sarı pas hastalığı ayırıcı seti, 2006-2016 üretim sezonları süresince sarı pas hastalığının dominant ırk/ırklarına karşı sera ve tarla şartlarındaki reaksiyonları belirlenmiştir. Tüm üretim sezonları süresince gerek fide evresi gerekse ergin bitki evresinde hassas kontrol grubu genotiplerinin reaksiyonları hassas grupta yer almıştır. Bu nedenle tüm yıllar ve tüm evre çalışmalarının güvenilir bir şekilde gerçekleştirildiği kabul edilmiştir. Dayanıklı olarak seçilen 61 genotip tüm üretim sezonları süresince gerek fide evresi gerekse ergin bitki evresinde ki reaksiyonları dayanıklı grupta yer almıştır. Hastalığa dayanıklı makarnalık genotiplerinin sarı pas hastalığına dayanıklılık özelliği yönünden gruplandırmak amacıyla oluşturulan gruplar ile önceki yıllarda kullanılan hastalık reaksiyon gruplarının yüksek oranda benzerlik içerisinde olduğu tespit edilmiştir (Çizelge 2). Sarı pas hastalığı popülasyonun, ayırıcı set üzerinde etkin (virülent) veya etkin olmadığı (avirülent) ve dayanıklılık genlerinin ifade edilmesinde "Global Rust Reference Center" tarafında geliştirilen yöntem uygulanmıştır. Buna göre;

2006-2010 yılları süresince (İolat 1) Yr-, 2,-, -,-, 6, 7, 8, 9, -, -, -, -, 25, -, -, -, ve AvS dayanıklılık genleri üzerine etkin (virülent) olduğu,

2011-2014 yılları süresince (İzolat 2) Yr-, 2,-, $---, 6,7,8,9,-,--,--, 25,-, 27,-, S u, S D$, ve AvS dayanıklılık genleri üzerine etkin (virülent) olduğu,

2014-2015 üretim sezonunda (Izolat 3) 1, 2, 3, 4, - , 6, 7, - , 9, - - - 17, -, 25, -, 32, Sp, ve AvS (SU, $S D, 3 N, 3 V$ ),-ve $A v S$ dayanıklılık genleri üzerine etkin (virülent) olduğu belirlenmiştir. 
Türk Tarım ve Doğa Bilimleri Dergisi 6(4): 661-670, 2019

Çizelge 2. Tüm yıllar ve tüm izolatlara karşı fide evresi ve ergin bitki evresinde test materyalinin reaksiyonları

\begin{tabular}{|c|c|c|c|c|c|c|c|c|c|c|c|c|c|c|}
\hline Evre & Fide E.* & Fide $\mathrm{E}$. & Fide $\mathrm{E}$. & Ergin E. & Ergin $\mathrm{E}$. & Ergin E. & Ergin E. & Ergin E. & Ergin E. & Ergin E. & Ergin E. & Ergin E. & Ergin E. & Ergin $\mathrm{E}^{*}$ \\
\hline S. No/Yıllar & İzolat 3 & İzolat 2 & İzolat 1 & 2016 EK & 2015 EK & 2014 EK & 2013 EK & 2012 EK & 2011 EK & 2010 EK & 2009 EK & 2008 EK & 2007 EK & $2006 \mathrm{EK}$ \\
\hline 01 & 0 & 0 & 0 & 0.8 & 0.8 & 0 & 0 & 0 & 0 & 0.8 & 0.8 & 0.8 & 0.8 & 0.8 \\
\hline 02 & 1 & 0 & 0 & 0.8 & 0 & 0 & 0 & 0 & 0 & 0.8 & 0.8 & 0.8 & 0.8 & 0.8 \\
\hline 03 & 1 & 0 & 0 & 0.8 & 0 & 0 & 0 & 0 & 0 & 0.8 & 0.8 & 0.8 & 0.8 & 0.8 \\
\hline 04 & 1 & 1 & 2 & 0 & 0 & 0 & 0 & 0 & 0 & 0.8 & 0.8 & 0.8 & 0.8 & 0.8 \\
\hline 05 & 1 & 1 & 2 & 0 & 0 & 0 & 0 & 0 & 0 & 0.8 & 0.8 & 0.8 & 0.8 & 0.8 \\
\hline 06 & 1 & 0 & 0 & 0.8 & 0 & 0 & 8.4 & 0 & 0 & 0.8 & 0.8 & 0.8 & 0.8 & 0.8 \\
\hline 07 & 0 & 0 & 0 & 0.8 & 0 & 0 & 0 & 0 & 0 & 0.8 & 0.8 & 0.8 & 0.8 & 0.8 \\
\hline 08 & 0 & 0 & 0 & 0 & 0 & 0 & 0 & 0 & 0 & 0.8 & 0.8 & 0.8 & 0.8 & 0.8 \\
\hline 09 & 3 & 5 & 6 & 0 & 0 & 0 & 0 & 0 & 0.8 & 0.8 & 0.8 & 0.8 & 0.8 & 0.8 \\
\hline 10 & 1 & 1 & 0 & 0 & 0 & 0 & 0 & 0 & 0.8 & 0.8 & 0.8 & 0.8 & 0.8 & 0.8 \\
\hline 11 & 1 & 0 & 0 & 0 & 0 & 0 & 0 & 0 & 0 & 0.8 & 0.8 & 0.8 & 0.8 & 0.8 \\
\hline 12 & 6 & 5 & 6 & 0.8 & 0.8 & 0 & 0 & 0 & 0.8 & 0.8 & 0.8 & 0.8 & 0.8 & 0.8 \\
\hline 13 & 6 & 5 & 6 & 0 & 0 & 0 & 0 & 0 & 0 & 0.8 & 0.8 & 0.8 & 0.8 & 0.8 \\
\hline 14 & 1 & 0 & 0 & 0.8 & 0.8 & 0 & 0 & 0 & 0 & 0.8 & 0.8 & 0.8 & 0.8 & 0.8 \\
\hline 15 & 0 & 1 & 2 & 0.8 & 0.8 & 0 & 0 & 0 & 0 & 0.8 & 0.8 & 0.8 & 0.8 & 0.8 \\
\hline 16 & 5 & 5 & 6 & 8 & 8 & 0 & 0 & 0 & 0.8 & 0.8 & 0.8 & 0.8 & 0.8 & 0.8 \\
\hline 17 & 0 & 1 & 0 & 0 & 0 & 0 & 0 & 0 & 0 & 0.8 & 0.8 & 0.8 & 0.8 & 0.8 \\
\hline 18 & 0 & 1 & 0 & 0 & 0 & 0 & 0 & 0 & 0 & 0.8 & 0.8 & 0.8 & 0.8 & 0.8 \\
\hline 19 & 1 & 2 & 0 & 0 & 0 & 8.4 & 8 & 0 & 0 & 0.8 & 0.8 & 0.8 & 0.8 & 0.8 \\
\hline 20 & 0 & 1 & 0 & 0.8 & 0 & 0 & 0 & 0 & 0 & 0.8 & 0.8 & 0.8 & 0.8 & 0.8 \\
\hline 21 & 1 & 1 & 0 & 0.8 & 0 & 0 & 0 & 0 & 0 & 0.8 & 0.8 & 0.8 & 0.8 & 0.8 \\
\hline 22 & 1 & 1 & 0 & 0.8 & 0 & 0 & 0.8 & 0.8 & 0 & 0.8 & 0.8 & 0.8 & 0.8 & 0.8 \\
\hline 23 & 1 & 1 & 0 & 0 & 0 & 0 & 0 & 0 & 0 & 0.8 & 0.8 & 0.8 & 0.8 & 0.8 \\
\hline 24 & 0 & 2 & 0 & 0 & 0 & 0 & 0 & 0 & 0 & 0.8 & 0.8 & 0.8 & 0.8 & 0.8 \\
\hline 25 & 0 & 1 & 1 & 0 & 0 & 0 & 8.4 & 0 & 0 & 0.8 & 0.8 & 0.8 & 0.8 & 0.8 \\
\hline 26 & 1 & 1 & 3 & 0.8 & 0.8 & 0 & 0 & 0 & 0 & 0.8 & 0.8 & 0.8 & 0.8 & 0.8 \\
\hline 27 & 0 & 1 & 1 & 0 & 0 & 0 & 0 & 0 & 0 & 0.8 & 0.8 & 0.8 & 0.8 & 0.8 \\
\hline 28 & 1 & 1 & 0 & 0 & 0 & 8 & 0 & 0 & 0 & 0.8 & 0.8 & 0.8 & 0.8 & 0.8 \\
\hline 29 & 1 & 3 & 4 & 4.4 & 4.4 & 0.8 & 8.4 & 0.8 & 0 & 0.8 & 0.8 & 0.8 & 0.8 & 0.8 \\
\hline 30 & 6 & 2 & 6 & 4.4 & 4.4 & 4.4 & 8 & 4.4 & 8,4 & 0.8 & 0.8 & 0.8 & 0.8 & 0.8 \\
\hline 31 & 0 & 2 & 1 & 0 & 0 & 0 & 0 & 0 & 0 & 0.8 & 0.8 & 0.8 & 0.8 & 0.8 \\
\hline
\end{tabular}

*Fide E.: Fide evresi; Ergin E.: Ergin evresi; 
Türk Tarım ve Doğa Bilimleri Dergisi 6(4): 661-670, 2019

Çizelge 2 (Devamı). Tüm yıllar ve tüm izolatlara karşı fide evresi ve ergin bitki evresinde test materyalinin reaksiyonları

\begin{tabular}{|c|c|c|c|c|c|c|c|c|c|c|c|c|c|c|}
\hline Evre & Fide E.* & Fide E. & Fide E. & Ergin $\mathrm{E}$. & Ergin $\mathrm{E}$. & Ergin $\mathrm{E}$. & Ergin E. & Ergin $\mathrm{E}$. & Ergin $\mathrm{E}$. & Ergin E. & Ergin $\mathrm{E}$. & Ergin E. & Ergin $\mathrm{E}$. & Ergin $\mathrm{E}^{*}$ \\
\hline S. No/Yıllar & İzolat 3 & İzolat 2 & İzolat 1 & 2016 EK & 2015 EK & 2014 EK & 2013 EK & 2012 EK & 2011 EK & 2010 EK & 2009 EK & 2008 EK & 2007 EK & 2006 EK \\
\hline 32 & 1 & 3 & 1 & 0 & 0 & 0 & 0 & 0 & 0 & 0.8 & 0.8 & 0.8 & 0.8 & 0.8 \\
\hline 33 & 0 & 1 & 0 & 0.8 & 0 & 4.4 & 0 & 0 & 0 & 0.8 & 0.8 & 0.8 & 0.8 & 0.8 \\
\hline 34 & 0 & 1 & 1 & 0.8 & 0 & 0 & 0 & 0 & 0 & 0.8 & 0.8 & 0.8 & 0.8 & 0.8 \\
\hline 35 & 1 & 1 & 1 & 0 & 0 & 0 & 0 & 0 & 0 & 0.8 & 0.8 & 0.8 & 0.8 & 0.8 \\
\hline 36 & 0 & 1 & 0 & 0.8 & 0 & 0 & 0 & 0 & 0 & 0.8 & 0.8 & 0.8 & 0.8 & 0.8 \\
\hline 37 & 0 & 2 & 1 & 0 & 0 & 0 & 0 & 0 & 0 & 0.8 & 0.8 & 0.8 & 0.8 & 0.8 \\
\hline 38 & 2 & 3 & 5 & 8 & 8 & 8.4 & 8 & 0 & 0 & 0.8 & 0.8 & 0.8 & 0.8 & 0.8 \\
\hline 39 & 1 & 3 & 0 & 0 & 0 & 0 & 0 & 0 & 0 & 0.8 & 0.8 & 0.8 & 0.8 & 0.8 \\
\hline 40 & 1 & 3 & 3 & 0.8 & 0.8 & 0 & 0 & 0 & 0 & 0.8 & 0.8 & 0.8 & 0.8 & 0.8 \\
\hline 41 & 0 & 0 & 0 & 0 & 0 & 0 & 0 & 0 & 0 & 0.8 & 0.8 & 0.8 & 0.8 & 0.8 \\
\hline 42 & 2 & 3 & 1 & 0.8 & 0.8 & 0 & 8 & 0 & 8 & 0.8 & 0.8 & 0.8 & 0.8 & 0.8 \\
\hline 43 & 1 & 2 & 1 & 0 & 0 & 0 & 0.8 & 0.8 & 0 & 0.8 & 0.8 & 0.8 & 0.8 & 0.8 \\
\hline 44 & 1 & 6 & 6 & 0 & 0 & 0 & 0 & 0 & 0 & 0.8 & 0.8 & 0.8 & 0.8 & 0.8 \\
\hline 45 & 0 & 1 & 1 & 0 & 0 & 0 & 0 & 0 & 0 & 0.8 & 0.8 & 0.8 & 0.8 & 0.8 \\
\hline 46 & 4 & 0 & 0 & 4.4 & 4.4 & 0 & 0 & 0 & 0 & 0.8 & 0.8 & 0.8 & 0.8 & 0.8 \\
\hline 47 & 3 & 3 & 3 & 4.4 & 4.4 & 0 & 0 & 0 & 0 & 0.8 & 0.8 & 0.8 & 0.8 & 0.8 \\
\hline 48 & 2 & 2 & 1 & 0 & 0 & 0 & 0 & 0 & 0 & 0.8 & 0.8 & 0.8 & 0.8 & 0.8 \\
\hline 49 & 0 & 1 & 1 & 0 & 0 & 0.8 & 0 & 0 & 0 & 0.8 & 0.8 & 0.8 & 0.8 & 0.8 \\
\hline 50 & 0 & 1 & 1 & 0 & 0 & 0 & 0 & 0 & 0 & 0.8 & 0.8 & 0.8 & 0.8 & 0.8 \\
\hline 51 & 1 & 1 & 1 & 0 & 0 & 0 & 0 & 0 & 0 & 0.8 & 0.8 & 0.8 & 0.8 & 0.8 \\
\hline 52 & 0 & 0 & 0 & 0 & 0 & 0 & 0 & 0 & 0 & 0.8 & 0.8 & 0.8 & 0.8 & 0.8 \\
\hline 53 & 0 & 0 & 0 & 0 & 0 & 0 & 0 & 0 & 0 & 0.8 & 0.8 & 0.8 & 0.8 & 0.8 \\
\hline 54 & 3 & 3 & 1 & 0 & 0 & 0 & 0 & 0 & 0 & 0.8 & 0.8 & 0.8 & 0.8 & 0.8 \\
\hline 55 & 0 & 0 & 0 & 0 & 0 & 0 & 0 & 0 & 0 & 0.8 & 0.8 & 0.8 & 0.8 & 0.8 \\
\hline 56 & 6 & 6 & 6 & 4.4 & 4.4 & 0 & 0 & 0 & 0 & 0.8 & 0.8 & 0.8 & 0.8 & 0.8 \\
\hline 57 & 1 & 0 & 0 & 0 & 0 & 0 & 0 & 0 & 0 & 0.8 & 0.8 & 0.8 & 0.8 & 0.8 \\
\hline 58 & 6 & 6 & 6 & 4.4 & 4.4 & 0 & 0 & 4.4 & 0 & 0.8 & 0.8 & 0.8 & 0.8 & 0.8 \\
\hline 59 & 0 & 1 & 3 & 0 & 0 & 0 & 0 & 0 & 0 & 0.8 & 0.8 & 0.8 & 0.8 & 0.8 \\
\hline 60 & 0 & 1 & 1 & 0 & 0 & 0 & 0 & 0 & 0 & 0.8 & 0.8 & 0.8 & 0.8 & 0.8 \\
\hline 61 & 0 & 5 & 6 & 0 & 0 & 0 & 0 & 0 & 0 & 0.8 & 0.8 & 0.8 & 0.8 & 0.8 \\
\hline
\end{tabular}

*Fide E.: Fide evresi; Ergin E.: Ergin evresi; 
Gerek fide evresi gerekse ergin bitki evresi test materyalinin reaksiyonları Çizelge 2 de verilmiştir. Tüm üretim sezonları boyunca gerek fide evresi gerekse ergin bitki evresi testlerinde, reaksiyon testi yapılan 3 farklı sarı pas izolatına karşı tüm materyal dayanıklı grupta yer almıştır. Ayrıca 3 hastalık popülasyonunun ırk/ırklarının $Y r 5,10,15$, 24, 26 ve 32 dayanıklılık genleri üzerine etkin olmadığı (avirülent olduğu) belirlenmiştir.

Araştırma da değerlendirilen genotiplerin tüm üretim yılları üzerinden yapılan değerlendirme sonucunda dayanıklı (R) grup da yer aldığı belirlenmiştir. Biplot grafiğin en sol kısmında kalan ve reaksiyonları değişmeyen ya da 0'a yakın değeri olan genotipler reaksiyonu en az değişen grubu oluştururken, tüm yıllar ve tüm izolatlara karşı en yüksek hastalık reaksiyonuna sahip olan dayanıklı materyal (örneğin 30 ve 58 nolu dayanıklı genotipler) en sağ bölümde (en dış) yer almış olup reaksiyonu en fazla değişen genotipler olarak öne çıkmışlardır (Şekil 1).

Test materyali tek başaktan üretildiği için, herhangi bir genetik açılma (heterozigotluk) ve mekanik karışıklık belirlenmemiştir. Diğer taraftan sadece bir izolata karşı dayanıklı olarak seçilen materyalin tüm üretim sezonları boyunca gerek fide evresi gerekse ergin bitki evresi testlerinde, reaksiyon testi yapılan diğer 2 farklı sarı pas hastalığı izolatına karşı da dayanıklı grupta yer alması dikkat çekicidir. Tunus da fide evresinde gerçekleştirilen farklı bir çalışmada; 39 Tunus yerel makarnalık buğday aksesyonu bölgede dominant olan 3 Irka, (Warrior1 (W1), Warrior- (W-) ve Triticale 2006) karşı test edilmiş ve test edilen materyalin sera şartlarında \%10'nunun 3 ırka dayanıklı olduğu tespit edilmiştir (Bahri ve ark., 2016). Tunus da fide evresinde yapılan bu çalışmada, hastalığa dayanıklılık açısından hiç seleksiyon yapılmadan bile 39 yerel makarnalık buğday aksesyonundan \%10'nun 3 dominant ırka karşı dayanıklı olduğu belirlenmiştir. Bu çalışmada dayanıklı gruba giren genotip sayısının azlığı çalışmaya hiç seçim yapılmadan başlanması ve kullanılan genotiplerin ıslah sürecine girmeyen köy çeşitlerinin kullanılması neden olabilir.

Çalışmada kullanılan hatların seçimi 2006 üretim sezonun da tamamlanmış olup Orta Anadolu yetiştiricilik şartlarında 1995-2010 yılı üretim sezonlarında dominant hastalık popülasyonuna (izolat-1) göre yapılmıştır. Daha sonra dayanıklı grupta yer alan hatlar 2011-2014 yılı üretim sezonlarında dominant hastalık popülasyonuna (izolat-2) karşıda test edilmiş ve materyalin tümü yine dayanıklı grupta yer almıştır. Çalışmanın sonunda ise her iki izolata karşı da dayanıklı grup da yer alan materyal 2015-2016 yılı üretim sezonlarında dominant hastalık popülasyonuna (izolat-3) karşıda test edilmiş ve materyalin tümü yine dayanıklı grupta yer almıştır. Hastalık popülasyonun etkili olduğu dayanıklılık genlerinin de belirlendiği çalışmada özellikle 2011 yılı ve sonrası "Global Rust Reference Center" tarafından yapılan ırk analizi çalışmaları ile benzerlik göstermektedir (Anonim, 2018e). Çalışma sonucu dominant 3 hastalık popülasyonunun $Y r 5,10,15$, 24,26 ve 32 dayanıklılık genleri üzerine etkin olmadığı (avirülent olduğu) belirlenmiştir.

Sarı pas hastalığının farklı dominant ırk/ırklarına karşı hastalık reaksiyonlarına göre oluşturulan GGE-biplot grafiğinin, hastalığa dayanıklılık ıslah programlarında sarı pas hastalığına dayanıklı genotiplerin belirlenerek seçilmesi amacıyla etkin bir şekilde kullanılabilir. Farklı çalışmalarda, hastalık değerlendirmelerinin skorlarına göre; genotiplerin değerlendirilebileceği ortaya konulmuştur (Yan ve Kang, 2003; Yan, 2014).

Biplot grafiğinde düşük PC1 (negatif değerler) ve 0.0 değerine yakın PC2 değerleri genotiplerin sarı pas hastalığına dayanıklılığı en uygun şekilde açıklamıştır. Hastalıklara dayanıklılık açısında ideal genotipi belirlemede kullanılan ortalama çevre ekseni (Avarage Environment Axis) odak alarak oluşturulan çemberler ise seleksiyon özelliği yönüyle biplot grafiğinin etkinliğini artırmıştır. Grafikte iç içe çizilmiş çemberlerden meydana gelen (Şekil 1) toplam altı bölüm oluşmuş, bu bölümlerin hastalığa dayanıklııı reaksiyon grupları ile birlikte değerlendirilmiştir. Genotiplerin sarı pas hastalığına dayanıklılığı sağ bölüme doğru azalmıştır. Yani birinci çemberin oluşturduğu birinci bölüm içerisinde en dayanıklı genotipler yer alırken ( $E K=1.8$ - 5.4 oranında hastalık enfeksiyonu), en son bölüm içerisinde daha hassas (kabul edilebilir düzeyde dayanıklı grupta yer almaktadır) genotipler ( $\geq$ EK5.4 hastalık enfeksiyonu) yer almıştır. Hastalığa dayanıklı grup olan 0.1-5.0 Enfeksiyon katsayısı grubuna dahil 52 genotip birinci bölümde, orta dayanıklı olarak enfeksiyon katsayısı 5.1-20.0 olarak tanımlanan (Akan ve Akçura, 2018) 9 genotip diğer bölümler içerisinde yer almıştır. Özellikle tüm yetiştirme sezonlarında hastalık reaksiyon ortalaması birbirine yakın olan genotiplerden, herhangi bir yetiştirme sezonunun birisinde enfeksiyon değeri yüksek veya düşük olanların konumu grafiğin merkezinden uzak konumda yer almaktadır. Grafikte en soldaki kısımda genotiplerin her üç genotipe karşı hastalık reaksiyonları değişmeyen 0.1'e yakın değere sahip olanlar, grafikte en sağda (en dışta) yer alan genotipler (örneğin 58 ve 30 gibi), reaksiyonu en çok değişen genotipler olarak öne çıkmaktadırlar. 
Grafik üzerinde izolatların konumları incelediğinde ise, her üç izolat arasında ayrıcı set üzerinde yapılan değerlendirme sonucu önemli farklıklar içerdiği ortaya konulsa da, her üç ırkın da aynı daire içinde olduğu ve yakın konumlarda olduğu görülmektedir (Şekil 1). Bu durum farklı izolatlarla yapılan çalışmalarda GGE-biplot analizin farklılı̆ı belirlemede yeterli olamayacağını göstermektedir.

Grafik üzerinde yılların konumları incelediğinde ise, 2006-2010 yılları aynı nokta da yer alırken, farklı izolatlarla reaksiyon çalışmalarının yapıldığı 2011 ve 2015 yılları çalışmaları ise diğer yıllardan farklı yerlerde yer almaktadır (Şekil 1). Bu farklılık beklenilen bir durum olup gerek yapay epidemi, gerekse doğal epidemi şartlarında aynı üretim alanında farklı izolatların farklı oranlarda materyali etkileme ihtimalinden kaynaklanmış olabilir. Çalışma sonucu çalışma materyalinin tüm üretim sezonlarına göre sarı pas hastalığı reaksiyonlarındaki değişimine bağlı olarak genotiplerin reaksiyonlarının grafikteki konumu ortalama çevre ekseni'ne (Avarage Environment Axis) yaklaşmış ya da uzaklaşmıştır. Ancak, bu değişimlerde dayanıklı genotiplerin hastalık reaksiyonlarının düşük ya da yüksek olması en belirgin faktör olmuştur. Diğer taraftan, yetiştirme sezonlarına göre hastalık oranı bakımından yapılan değerlendirmede en az bir üretim sezon reaksiyonu ya da genel ortalama olarak birinci çemberin içinde yer alan en dayanıklı gruptan ayrılmışlardır. Bu grup buğday ıslah çalışmalarında hastalıklara dayanıklııı kaynağı olarak varyasyon oluşturmak amacıyla kullanılabilecek en ideal genetik kaynak olarak değerlendirilebilir. Nitekim sarı pas hastalığı, dayanıklılık ıslah çalışmalarında dayanıklılık kaynağı olarak kullanılan materyal olarak, yürütülen bir araştırmada enfeksiyon katsayısı 20.0 ve altında olan genotipler dayanıklı olarak değerlendirilmektedir (Akan ve Akçura, 2018).

\section{Sonuç ve Öneriler}

Türkiye'de sarı pas hastalığı, özellikle serin ve nemli koşullarda çok etkili olabilmektedir. Özellikle hastalığın epidemi oluşturduğu üretim sezonlarında ürün verim ve kalitesini olumsuz yönde ve farklı düzeylerde etkilemekte olup değişen düzeylerde ekonomik kayıplara yol açmaktadır. Hastalığın kontrolünde dayanıklı çeşitlerin kullanımı üretici tarafından öncelikle tercih edilmekte olup, bu özelliğe sahip çeşitlerin üretim deseninde yer alması hastalığın kontrolünde pratik ve ekonomik bir uygulama olarak öne çıkmaktadır. Dayanıklı çeşit geliştirilmesi için öncelikle hastalığın değişen hastalık popülasyonlarına karşı kabul edilebilir düzeyde dayanıklı, geniş bir germplasm'a sahip olunması gerekliliği açıktır.
Çalışma sonucunda kabul edilebilir düzeyde dayanıklı olarak seçilmiş olan materyalin dane verimi ve kalitesi ile morfolojik özellikleri de yeni çeşit geliştirme potansiyeline sahip 61 hat arasından seçilecek hatlar sarı pasa dayanıklı yeni makarnalık çeşitlerin geliştirilmesinde ıslah programlarında anaç olarak değerlendirilebilir.

\section{Teşekkür}

$\mathrm{Bu}$ çalışma Tarımsal Araştırmalar ve Politikalar Genel Müdürlüğünce desteklenmiştir. Genetik materyali geliştiren ve dayanıklılık testlemelerini yapan uluslararası ve ulusal programlara ve özellikle de Tarla Bitkileri Merkez Araştırma Enstitüsü, Hastalık ve Zararlılara Dayanıklılık Birimi çalışanlarına teşekkürü bir borç bilirim.

\section{Kaynaklar}

Akan, K., Akcura, M. 2018. GGE biplot analysis of reactions of bread wheat pure lines selected from Central Anatolian landraces of Turkey to leaf rust disease (Puccinia triticina) in multiple location-years. Cereal Research Communications, 46(2): 311-320. https://doi.org/10.1556/0806.46.2018.12.

Akan, K., Mert, Z., Çetin, L., Salantur, A., Yazar, S., Dönmez, E., Özdemir, B., Yalçın, S., Özer, Y., Wanyera, R. 2012. Bazı buğday genotiplerinin lokal sarı pas ve kara pas ırklarıyla Ug99 Kara pas ırkına reaksiyonlarının belirlenmesi. Tarla Bitkileri Merkez Araştırma Enstitüsü Dergisi, 21(1): 22-31.

Aktaş, H. 2001. Önemli Hububat Hastalıkları ve Sürvey Yöntemleri Kitapçığı. Tarım ve Köyişleri Bakanlığı, Tarımsal Araştırmalar Genel Müdürlüğü, Bitki Sağlığı Araştırma Daire Başkanlığı, 80 s., Ankara.

Anonim, 2016. Ülkesel Serin Iklim Tahıl Hastalıkları Araştırma Projesi, 2015-2016 Yetiştirme sezonu Yıllık Raporu, TAGEM Yayınlanmamış.

Anonim, 2018a. 2017 Yılı Hububat Sektör Raporu, Toprak Mahsulleri Ofisi Genel Müdürlüğü. (http://www.tmo.gov.tr/Upload/Document /hububatsektorraporu2017.pdf, Erişim tarihi: 01.11.2018), $64 \mathrm{~s}$.

Anonim, 2018b. Türkiye İstatistik Kurumu, Bitkisel Üretim İstatistikleri (http://tuik.gov.tr/PreTablo.do?alt_id=1001 ¿Erişim tarihi: 01.11.2018).

Anonim, 2018c. Middle East: Yellow Rust Epidemic Affects Regional Wheat Crops (https://ipad.fas.usda.gov/highlights/2010/ 06/Middle\%20East/June 10, 2010, Erişim tarihi: 01.11.2018)

Anonim, 2018d. Zirai Mücadele Teknik Talimatları, 
Gıda Tarım ve Hayvancılık Bakanlığı Tarımsal Araştırmalar ve Politikalar Genel Müdürlüğü Yayınları. Cilt:1, 283 s., Ankara.

Anonim, 2018e. Race Analysis of Yellow Rust At GRRC (http://wheatrust.org/, Erişim tarihi: 01.11.2018).

Bahri, B., Leconte, M., Hamza, S., De Vallavieille Pope, C. 2016. Wheat yellow rust dynamics in Tunisia since 2013 and resistance genes in durum wheat. 2016 APS Annual Meeting. Poster: Biology \& Disease Mgmt: Genetics of Resistance, 342-P, 2016 APS Annual Meeting Presentations, Tampa, FL, USA, July 3 August 3, 2016.

Braun, H.J., Saari, E.E. 1992. An assessment of the potential of Puccinia striiformis $\mathrm{f}$. $\mathrm{sp}$. tritici to cause yield losses in wheat on the Anatolian plateau of Turkey. Vortr. Planzenzuchhtg, (24): 121-123.

Düşünceli, F., Cetin, L., Albustan, S., Beniwal, S.P.S. 1996. Occurrence and impact of wheat stripe rust (Puccinia striiformis) in Turkey in 1994/95 crop season. Cereal Rusts and Powdery Mildews Bulletin, 24: 309.

Düşünceli, F., Cetin, L., Albustan, S., Ekiz, H. 2000. Orta Anadolu buğday ekilişlerinde pas hastalıklarının (Puccinia spp.) yaygınlığı, önemi ve alınması gereken tedbirler. Orta Anadolu'da Hububat Tarımının Sorunlar ve Çözüm Yollar Sempozyumu, Konya, Türkiye, 8-11 Haziran 1999. s.693-696.

Dutlu, C. 1980. Buğday ıslahında sarı pasa dayanıklılığın genel esasları. Bitki Islahı Sempozyumu, Ege Bölge Zirai Araştırma Enstitüsü. Tarımsal Araştırmalar Genel Müdürlüğü Yayın No: 17/41, s.167-176.

İren, S. 1964. Türkiye'de 1963 yılı hububat pas türleri ve zarar ve yayılışları üzerinde araştırmalar. Bitki Koruma Bülteni, 4: 141159.

Mamluk, O.F., Çetin, L., Braun, H.J., Bolat, N., Bertschinger, L., Makkouk, K.M., Yıldırım, A.F., Saari, E.E., Zencirci, N., Albustan, S., Çalı, S., Beniwal, S.P.S., Düşünceli, F. 1997. Current status of wheat and barley diseases of Central Anatolian Plateau of Turkey. Phytopathology Medite., 36: 167-181.

McNeal, F.H., Konzak, C.F., Smith, E.P., Tate, W.S., Russell, T.S. 1971. A uniform system for recording and processing cereal research data. United States Department of Agriculture, Agricultural Research Service, 34: 121-43.

Mert, Z. 2010. Ülkesel Serin Iklim Tahıl Hastalıkları Araştırmaları Projesi. Serin İklim Tahılları Araştırmaları Program Değerlendirme Toplantısı, Antalya, Yayınlanmamış.
Özgen, M., Kınacı, E. 1985. Bitkilerde hastalıklara Dayanıklılık, Dayanıklılık Islahı Yöntemleri ve Yeni Gelişmeler. Buğday ve Mısır Hastalıkları Semineri, Ankara, s.69-86.

Pehlivan, A., Ünver İkincikarakaya, S. 2017. Makarnalık buğdayda kalite ıslahı çalışmaları. Tarla Bitkileri Merkez Araştırma Enstitüsü Dergisi, 26(1): 127-151.

Peterson, R.F., Campbell, A.B., Hannah, A.E. 1948. A diagrammatic scale for estimating rust intensity on leaves and stems of cereals. Canadian Journal of Research Section C., 26: 496-500.

Yan, W. 2014. Crop Variety Trials: Data Management and Analysis. John Wiley and Sons. pp. 349.

Yan, W., Falk, D.E. 2002. Biplot analysis of host-bypathogen data. Plant Disease, 86: 13961401.

Yan, W., Kang, M.S. 2003. GGE Biplot Analysis: A Graphical Tool for Breeders, Geneticists, and Agronomists. CRC Press, Boca Raton, FL.

Yan, W., Kang, M.S., Ma, B. Woods, S., Cornelius, P.L. 2007. GGE-Biplot vs. AMMI analysis of genotype by-environment data. Crop Science, 47: 643-655.

Yau, S.K. 1995. Regression and AMMI analyses of genotype $\mathrm{x}$ environment interactions: An empirical comparison. Agronomy Journal, 87(1): 121-126.

Zadoks, J.C., Chang, T.T., Konzak, C.F. 1974. A decimal code for the growth stages of cereals. Weed Research, 14: 415-421. 